\title{
BMJ Open Sex differences in non-communicable disease prevalence in China: a cross- sectional analysis of the China Health and Retirement Longitudinal Study
} in 2011

\author{
Yan Liu, ${ }^{1}$ Guofeng Liu, ${ }^{1}$ Hongjiang Wu, ${ }^{2}$ Weiyan Jian, ${ }^{1}$ Sarah $\mathrm{H}$ Wild, ${ }^{2}$ \\ Danijela Gasevic ${ }^{2}$
}

To cite: Liu Y, Liu G, Wu H, et al. Sex differences in non-communicable disease prevalence in China: a cross-sectional analysis of the China Health and Retirement Longitudinal Study in 2011. BMJ Open 2017;7:e017450. doi:10.1136/ bmjopen-2017-017450

- Prepublication history and additional material for this paper are available online. To view these files, please visit the journal online (http://dx.doi org/10.1136/bmjopen-2017017450).

Received 24 April 2017 Revised 4 September 2017 Accepted 18 September 2017

CrossMark

${ }^{1}$ School of Public Health, Peking University, Beijing, China ${ }^{2}$ Usher Institute of Population Health Sciences and Informatics, University of Edinburgh, Edinburgh, UK

Correspondence to

Dr Weiyan Jian;

jianweiyan@bjmu.edu.cn

\section{ABSTRACT}

Objectives To describe the sex differences in the prevalence of non-communicable diseases (NCDs) in adults aged 45 years or older in China.

Design Cross-sectional study.

Setting Nationally representative sample of the Chinese population 2011.

Participants 8401 men and 8928 women over 45 years of age who participated in the first wave of the China Health and Retirement Longitudinal Study (CHARLS). Outcome measures Self-reported data on overall health and diagnosis of hypertension, dyslipidaemia, diabetes, heart disease, stroke, chronic lung disease, cancer or arthritis. Sex differences in NCDs were described using logistic regression to generate odds ratios $(\mathrm{OR})$ with adjustment for sociodemographic factors and healthrelated behaviours. All analyses were stratified by age group for 45-64-year-old and $\geq 65$-year-old participants. Results In both age groups, men reported better overall health than women. The crude prevalence of heart disease, cancer and arthritis was higher while that of stroke and chronic lung disease was lower in women than in men. After adjustment, ORs $(95 \% \mathrm{Cl})$ for the $45-64$ and $\geq 65$ yearage groups were 0.70 (0.58 to 0.84$)$ and 0.66 (0.54 to 0.80 ), respectively, for arthritis for men compared with women. In contrast, ORs were 1.66 (1.09 to 2.52) and 2.12 (1.36 to 3.30) for stroke and 1.51 (1.21 to 1.89) and 1.43 (1.09 to 1.88) for chronic lung disease for men compared with women. ORs for heart disease $(0.65$ (0.52 to 0.80$)$ ) were lower in men than in women only in the 45-64 year age group.

Conclusions Odds of arthritis were lower while those of stroke and chronic lung disease were higher in men than in women in both age groups. However, odds of heart disease were lower in men than in women, but only in the group of individuals aged 45-64 years.

\section{BACKGROUND}

Non-communicable diseases (NCDs) are one of the major health challenges worldwide. ${ }^{1}$ It has been estimated that 34.5 million deaths globally were due to NCDs in 2010, which
Strengths and limitations of this study

- The strength of the study lies in the use of a nationally representative sample of adults aged 45 years or older in China.

- The study is limited by its cross-sectional design, and recall bias may have arisen because the health outcomes and health-related behaviours were selfreported.

- The study is also limited by the differential opportunity to be diagnosed based on socioeconomic status and cultural norms around healthcare seeking.

There is potential for residual confounding.

reflected a significant increase from $1990 .^{2}$ Furthermore, previous research across the world has revealed significant differences in health status and NCD prevalence between men and women. ${ }^{3-5}$ Women are more likely than men to report worse overall health and to have disabling non-lethal conditions including functioning problems globally. ${ }^{67}$

The rising burden of NCDs is particularly marked in low- and middle-income countries. ${ }^{1}$ One such country is China where the morbidity and mortality related to NCDs has increased markedly during the past two decades. In 2014, the age-standardised death rate for NCDs reached 636 per 100 000 people, accounting for $87 \%$ of all-cause mortality. ${ }^{8}$ A greater increase in self-reported chronic disease prevalence in China was observed among women than men between 2003 and 2008. ${ }^{9}$ In 2012, the average life expectancy was 72 years in Chinese men and 77 years in Chinese women. ${ }^{10}$ In nationally representative studies of adults the prevalence of diabetes in 2007-8 and hypertension in 2010 was significantly higher among men than among women in China. ${ }^{11-13}$ Chronic 
obstructive pulmonary disease (COPD) was also more prevalent among men than among women aged 40 years and older in China. ${ }^{14}$ Furthermore, lung cancer has been identified as the most common cancer among Chinese men while breast cancer was the most common cancer among Chinese women. ${ }^{15}$

While there have been many studies examining sex differences in the prevalence of NCDs in China, more recent studies of nationally representative populations are scarce. Therefore, the aim of this study is to describe the sex differences in NCD prevalence in adults aged 45 years or older in China using data collected in 2011 in the first wave of the nationally representative China Health and Retirement Longitudinal Study (CHARLS).

\section{METHODS \\ Data}

For this cross-sectional study we analysed baseline data of the China Health and Retirement Longitudinal Study (CHARLS), which is a nationally representative longitudinal survey of the mainland Chinese population aged 45 years or older. The baseline survey was conducted in 2011 with subsequent follow-up surveys planned every 2 years. In 2011, after excluding empty or non-resident dwellings, individuals from 12740 households were assigned as potential study participants. Final interviews were conducted in 17708 respondents from 10257 households in urban and rural areas in 150 of the 1442 counties and in 28 of the 34 provincial level administrative divisions in China.

The core CHARLS questionnaires included sections requesting information on: demographic factors, family structure and changes, health status and functioning, healthcare and insurance, work, retirement and pension, income and consumption, and assets (individual and household). Information was collected by interview by trained staff. The CHARLS team created separate weights for households and individuals corrected for non-response and sampling frame errors in each step of the CHARLS. Individuals recruited in 2011 were eligible for this analysis if they were aged 45 or older and had complete data on sex, health outcomes and individual weights. Details of the sampling methodology and the core CHARLS questionnaire have been described previously. ${ }^{16}$

\section{Variables}

For this study the following data were used: sociodemographic factors including age (middle-aged (45-64 years) and elderly ( $\geq 65$ years)), sex, formal level of education (no formal education, elementary school, middle school, high school/vocational school, associate degree or over), marital status (never married, married, separated/divorced, widowed) and regional location (eastern, central and western China). Health status included self-reported data on overall health (excellent, very good, good, fair, poor or very poor) and on whether the respondent had been diagnosed by a doctor with hypertension, dyslipidaemia (elevation of LDL-C, triglycerides, total cholesterol or low HDL-C), diabetes, heart disease (defined as heart attack, coronary heart disease, angina, congestive heart failure or other heart problems), stroke, chronic lung diseases (such as chronic bronchitis or emphysema but excluding cancer), cancer or arthritis. The study participants also reported whether they received treatment for any of the conditions diagnosed by their doctor, health-related behaviours including three independent categories of physical activity (PA) (doing vigorous PA or not, doing moderate PA or not, walking or not), smoking status (current smoker, former smoker, non-smoker), alcohol consumption (more than once a month, less than once a month, never) and the number of meals eaten per day. All study participants signed informed consent to participate and the study was approved by Peking University Biomedical Ethics Committee (IRB00001052-14013-exemption).

\section{Statistical analysis}

Due to low frequencies in some of the cells, we merged some of the categories in variables representing smoking, alcohol consumption, meals per day and self-reported health. The new variable for meals, smoking and drinking were binary variables (two meals or less per day vs three meals or more per day; smoking (current smoker) vs not smoking (former smoker, non-smoker); drinking alcohol (drink alcohol more than once a month) vs not drinking alcohol (drink alcohol but less than once a month, none of these) ). We also created a new self-reported health variable consisting of four categories: excellent/very good, good, fair and poor/very poor health.

All analyses were stratified by age group for 45-64 and $\geq 65$-year-old participants. All variables were categorical and are presented as counts and percentages, respectively. Sex differences in participants' characteristics were explored using $\chi^{2}$ tests. The association between sex and health outcomes was explored using logistic regression with three models. In Model 1, a crude model, we explored how health outcomes differ by sex while ignoring potential confounders. In Model 2 we included potential confounders including education level, marital status, region in China and urban status. Health-related behaviours have been identified as risk factors contributing to chronic NCDs, ${ }^{17}$ therefore Model 3 includes additional adjustment for physical activity (doing any PA (vigorous and/or moderate and/or walking) vs not doing any PA), smoking status, alcohol consumption and diet.

Individual weights in the CHARLS data were applied in all descriptions and analyses to take into account selection probability, non-response patterns and post-stratification factors. Taylor linearised variance estimation was used to take into account potential clustering as a result of the sampling strategy. All analyses were performed using STATA/SE Version 12.0 software. Tests were considered statistically significant if $\mathrm{P}<0.05$. 
Table 1 Sociodemographic characteristics of men and women in the CHARLS 2011

\begin{tabular}{|c|c|c|c|}
\hline & Men & Women & \multirow[b]{2}{*}{$P$ value } \\
\hline & $n=8401$ & $\mathrm{n}=8928$ & \\
\hline \multicolumn{4}{|l|}{ Age (years) } \\
\hline $45-64$ & $5747(68.1)$ & $6302(69.4)$ & \multirow[t]{2}{*}{0.0925} \\
\hline$\geq 65$ & 2654 (31.9) & 2626 (30.6) & \\
\hline Rural & 5098 (50.9) & 5239 (49.3) & 0.0037 \\
\hline \multicolumn{4}{|l|}{ Education } \\
\hline No formal education & $1083(11.7)$ & 3648 (38.8) & \multirow[t]{5}{*}{$<0.001$} \\
\hline Elementary school & 3696 (42.2) & $3084(33.7)$ & \\
\hline Middle school & $2216(26.4)$ & $1372(16.4)$ & \\
\hline $\begin{array}{l}\text { High school/ } \\
\text { vocational school }\end{array}$ & 1107 (15.3) & $676(8.8)$ & \\
\hline $\begin{array}{l}\text { Associate degree or } \\
\text { over }\end{array}$ & $288(4.4)$ & $132(2.3)$ & \\
\hline \multicolumn{4}{|l|}{ Marital status } \\
\hline Never married & $141(1.8)$ & $17(0.4)$ & \multirow[t]{4}{*}{$<0.001$} \\
\hline Married & 7617 (89.4) & 7474 (81.6) & \\
\hline Separated/divorced & $137(2.3)$ & $89(1.1)$ & \\
\hline Widowed & $505(6.6)$ & 1345 (16.9) & \\
\hline \multicolumn{4}{|l|}{ Region location } \\
\hline Eastern China & 2562 (36.6) & 2716 (35.6) & \multirow[t]{3}{*}{0.1541} \\
\hline Middle China & 3132 (34.0) & 3302 (34.2) & \\
\hline Western China & 2707 (29.5) & 2910 (30.2) & \\
\hline
\end{tabular}

Categorical variables presented as $\mathrm{n}(\%)$, with $\mathrm{n}$ being unweighted frequency and $\%$ being weighted column percentage.

$P$ values are for $\chi^{2}$ tests.

Missing data: education 27, marriage status 4 .

\section{RESULTS}

After excluding 379 participants with data missing on sex, health status and/or individual weights, a total of 17309 individuals (8401 men and 8928 women) were included in our analysis. Missing data across confounding variables are presented in online supplementary table S1.

Sociodemographic characteristics of study participants in the CHARLS 2011 are shown in table 1. There was no association of sex with age and region location in China. Compared with women, a greater proportion of men reported living in rural areas. Women were more likely to report a lower level of formal education than men, and a larger proportion of women reported having no formal education. Most men and women were married, but a larger proportion of men than women reported never being married, while a larger proportion of women than men reported being widowed.

Table 2 shows sex differences in health-related behaviours among Chinese men and women for middleaged and elderly groups. Compared with men, women aged 45-64 years were more likely to report engaging in walking. In contrast, in both age groups women were less likely to report engaging in vigorous physical activities than men. Self-reported tobacco smoking and alcohol consumption were substantially higher in men than in women. In addition, women were less likely to report consuming two meals or fewer per day than men in the middle-aged group, while the opposite was observed for the $\geq 65$ years age group.

Sex differences in self-reported health outcomes by age group are presented in table 3 . In both age groups, men reported better overall health than women. The prevalence of heart disease and arthritis was higher among women than men. The prevalence of cancer was higher in women than in men for the middle-aged group only. In contrast, the prevalence of chronic lung disease was higher among men than women for both age groups. No sex difference was observed in the prevalence of hypertension, dyslipidaemia and stroke for either age group.

We also explored age-adjusted sex differences in NCD treatment among men and women (see online supplementary table S2). Women reported higher use of both Chinese traditional and Western modern treatments for

Table 2 Prevalence of self-reported health-related behaviours among men and women in the CHARLS 2011

\begin{tabular}{|c|c|c|c|c|c|c|c|}
\hline & \multicolumn{3}{|l|}{ 45-64 years } & \multicolumn{3}{|l|}{$\geq 65$ years } \\
\hline & & \multirow{2}{*}{$\begin{array}{l}\text { Men } \\
n=5747\end{array}$} & \multirow{2}{*}{$\begin{array}{l}\text { Women } \\
n=6302\end{array}$} & \multirow[b]{2}{*}{$P$ value } & \multirow{2}{*}{$\begin{array}{l}\text { Men } \\
n=2654\end{array}$} & \multirow{2}{*}{$\begin{array}{l}\text { Women } \\
n=2626\end{array}$} & \multirow[b]{2}{*}{$P$ value } \\
\hline & & & & & & & \\
\hline Vigorous physical activity & & $986(15.1)$ & 867 (11.9) & $<0.001$ & $287(8.6)$ & $174(5.1)$ & $<0.001$ \\
\hline Moderate physical activit & & $1246(19.9)$ & $1651(25.2)$ & $<0.001$ & $495(16.4)$ & $418(13.6)$ & 0.0063 \\
\hline Walking & & $1683(28.4)$ & 2139 (34.2) & $<0.001$ & $830(29.5)$ & $756(27)$ & 0.054 \\
\hline Smoking & & $3091(57.1)$ & $304(4.1)$ & $<0.001$ & $1236(44.3)$ & $213(7.8)$ & $<0.001$ \\
\hline Alcohol consumption & & $3469(60.4)$ & $750(12.2)$ & $<0.001$ & $1208(45.8)$ & $296(10.5)$ & $<0.001$ \\
\hline \multirow[t]{2}{*}{ Number of meals per day } & $\leq 2$ & $1335(25.0)$ & $1204(19.8)$ & $<0.001$ & $584(23.6)$ & $627(27.1)$ & 0.0488 \\
\hline & $\geq 3$ & $4412(75.0)$ & 5098 (80.2) & & $2070(76.4)$ & 1999 (72.9) & \\
\hline
\end{tabular}

Categorical variables presented as $\mathrm{n}(\%)$, with $\mathrm{n}$ being unweighted frequency and \% being weighted percentage.

Differences in categorical variables explored by $\chi^{2}$ test.

Missing data: smoking status 689, alcohol consumption 44. 
Table 3 Prevalence of self-reported health outcomes among men and women in the CHARLS 2011

\begin{tabular}{|c|c|c|c|c|c|c|c|}
\hline & \multicolumn{3}{|l|}{ 45-64 years } & \multicolumn{3}{|l|}{$\geq 65$ years } \\
\hline & & \multirow{2}{*}{$\begin{array}{l}\text { Men } \\
n=5747\end{array}$} & \multirow{2}{*}{$\begin{array}{l}\text { Women } \\
n=6302\end{array}$} & \multirow[b]{2}{*}{$P$ value } & \multirow{2}{*}{\begin{tabular}{|l} 
Men \\
$n=2654$
\end{tabular}} & \multirow{2}{*}{$\begin{array}{l}\text { Women } \\
n=2626\end{array}$} & \multirow[t]{2}{*}{$P$ alue } \\
\hline & & & & & & & \\
\hline \multirow{4}{*}{$\begin{array}{l}\text { Reported } \\
\text { health }\end{array}$} & Very good & 604 (12.4) & $392(7.2)$ & $<0.001$ & $155(6.0)$ & $110(5.3)$ & $<0.001$ \\
\hline & Good & $1282(22.8)$ & $1088(19.0)$ & & 456 (18.5) & $349(13.6)$ & \\
\hline & Fair & $2863(49.2)$ & $3294(52.2)$ & & $1313(48.3)$ & $1236(46.5)$ & \\
\hline & Poor & $984(15.7)$ & $1514(21.7)$ & & $722(27.1)$ & $914(34.6)$ & \\
\hline \multicolumn{2}{|c|}{ Hypertension } & $1179(20.8)$ & $1384(21.9)$ & 0.3094 & 825 (36.3) & 986 (38.6) & 0.227 \\
\hline \multicolumn{2}{|c|}{ Dyslipidaemia } & $498(9.1)$ & $551(9.6)$ & 0.5086 & $240(10.8)$ & $291(12.4)$ & 0.2981 \\
\hline \multicolumn{2}{|c|}{ Heart disease } & $427(7)$ & $776(11.5)$ & $<0.001$ & $401(15.8)$ & $472(19.1)$ & 0.0414 \\
\hline \multicolumn{2}{|c|}{ Stroke } & $100(1.8)$ & $100(1.7)$ & 0.6874 & $115(5.1)$ & $94(3.8)$ & 0.0995 \\
\hline \multicolumn{2}{|c|}{ Diabetes } & $270(5.1)$ & $360(5.9)$ & 0.321 & $172(7.1)$ & $189(7.8)$ & 0.5405 \\
\hline \multicolumn{2}{|c|}{ Chronic lung disease } & $639(11.1)$ & $521(7.7)$ & $<0.001$ & $520(19.1)$ & $376(15)$ & 0.008 \\
\hline \multicolumn{2}{|l|}{ Cancer } & $34(0.5)$ & $83(1.2)$ & $<0.001$ & $26(1)$ & $33(1.2)$ & 0.549 \\
\hline \multicolumn{2}{|l|}{ Arthritis } & $1598(25.8)$ & 2211 (32.7) & $<0.001$ & $830(31.4)$ & $1077(39.4)$ & $<0.001$ \\
\hline
\end{tabular}

Categorical variables presented as $\mathrm{n}(\%), \mathrm{n}$, unweighted frequency; \%, weighted percentage.

Differences in categorical variables were explored by $\chi^{2}$ test.

arthritis and chronic lung diseases. Also, compared with men, women were more likely to report receiving no treatment for diabetes.
Table 4 shows the association (OR and relevant $\mathrm{CI}$ ) between sex and chronic NCDs stratified by age group. In the crude model, relative odds of heart disease and

Table 4 Results of logistic regression models describing the association between sex and self-reported health outcomes among participants in the CHARLS 2011

\begin{tabular}{|c|c|c|c|c|c|c|}
\hline & \multicolumn{6}{|c|}{ OR $(95 \% \mathrm{Cl})$ for men vs women } \\
\hline & \multicolumn{3}{|c|}{ 45-64 years $(n=12049)$} & \multicolumn{3}{|c|}{$\geq 65$ years $(n=5280)$} \\
\hline & Model A & Model B & Model C & Model A & Model B & Model C \\
\hline \multirow[t]{2}{*}{ Hypertension } & 0.94 & 0.91 & 1.08 & 0.91 & $0.85^{\star *}$ & 1.13 \\
\hline & (0.83 to 1.06$)$ & (0.79 to 1.04$)$ & (0.91 to 1.29$)$ & (0.77 to 1.06$)$ & (0.73 to 1.00$)$ & (0.95 to 1.36$)$ \\
\hline \multirow[t]{2}{*}{ Dyslipidaemia } & 0.94 & 0.88 & 1.05 & 0.86 & $0.60^{\star \star \star}$ & 0.86 \\
\hline & (0.78 to 1.13$)$ & (0.74 to 1.05$)$ & (0.85 to 1.29$)$ & (0.65 to 1.14$)$ & (0.43 to 0.84$)$ & (0.60 to 1.23$)$ \\
\hline \multirow[t]{2}{*}{ Heart disease } & $0.58^{\star \star \star}$ & $0.57^{\star \star \star}$ & $0.65^{\star \star \star}$ & $0.80^{\star \star}$ & $0.65^{\star \star \star}$ & 0.82 \\
\hline & (0.50 to 0.68$)$ & (0.48 to 0.66$)$ & (0.52 to 0.80$)$ & (0.64 to 0.99$)$ & (0.51 to 0.83 ) & (0.63 to 1.06$)$ \\
\hline \multirow[t]{2}{*}{ Stroke } & 1.07 & 1.13 & $1.66^{\star \star}$ & 1.35 & $1.63^{\star *}$ & $2.12^{\star \star \star}$ \\
\hline & (0.77 to 1.49$)$ & (0.79 to 1.60$)$ & (1.09 to 2.52$)$ & (0.94 to 1.92$)$ & (1.08 to 2.46$)$ & (1.36 to 3.30$)$ \\
\hline \multirow[t]{2}{*}{ Diabetes } & 0.87 & 0.92 & 1.39 & 0.91 & $0.69^{\star \star}$ & 1.06 \\
\hline & (0.66 to 1.15$)$ & (0.72 to 1.18$)$ & (0.96 to 2.02$)$ & (0.66 to 1.24 ) & (0.51 to 0.93 ) & (0.73 to 1.53 ) \\
\hline \multirow{2}{*}{$\begin{array}{l}\text { Chronic lung } \\
\text { disease }\end{array}$} & $1.49^{\star \star \star}$ & $1.66^{\star \star \star}$ & $1.51^{\star \star \star}$ & $1.34^{\star \star \star}$ & $1.39^{\star \star}$ & $1.43^{\star \star}$ \\
\hline & (1.23 to 1.81 ) & (1.37 to 2.01 ) & (1.21 to 1.89 ) & (1.08 to 1.66 ) & (1.08 to 1.80 ) & (1.09 to 1.88 ) \\
\hline \multirow[t]{2}{*}{ Cancer } & $0.41^{\star \star *}$ & $0.42^{\star \star \star}$ & 0.65 & 0.84 & $0.51^{* *}$ & 0.74 \\
\hline & (0.27 to 0.64$)$ & (0.26 to 0.68$)$ & (0.33 to 1.27 ) & (0.48 to 1.48$)$ & (0.27 to 0.97 ) & (0.36 to 1.52 ) \\
\hline \multirow[t]{2}{*}{ Arthritis } & $0.72^{\star \star \star}$ & $0.76^{\star \star \star}$ & $0.70^{\star \star \star}$ & $0.71^{\star \star \star}$ & $0.68^{\star \star \star}$ & $0.66^{\star \star \star}$ \\
\hline & (0.63 to 0.81$)$ & (0.66 to 0.87 ) & (0.58 to 0.84$)$ & (0.61 to 0.82$)$ & (0.57 to 0.80$)$ & (0.54 to 0.80$)$ \\
\hline
\end{tabular}

Binary logistic regression: Model A: crude model (no adjustment); Model B: adjusted for education, marital status, region in China and urban residence; Model C: adjustment as for model B with the addition of physical activity (doing any PA vs not doing any PA), smoking behaviour, alcohol consumption, and diet. Doing PA refers to doing any vigorous PA and/or moderate PA and/or walking.

${ }^{*} \mathrm{P}<0.1 ;{ }^{* \star} \mathrm{P}<0.05 ;{ }^{* \star *} \mathrm{P}<0.01$ 
arthritis were lower in men than in women, while those of chronic lung diseases were higher in men for both middle-aged and elderly groups. Odds of cancer were lower in men than in women in the middle-aged group. Adjustment for education, marital status, region in China and urban residence did not affect the abovementioned relationships between sex and health outcomes, and it additionally uncovered higher odds of stroke and lower odds of hypertension, dyslipidaemia, diabetes and cancer in elderly men compared with elderly women. In fully adjusted models, where models were additionally adjusted for health-related behaviours including physical activity, smoking status, alcohol consumption and diet, relative odds (middle-aged group/elderly group) of stroke (1.66 (95\% CI 1.09 to 2.52)/2.12 (95\% CI 1.36 to $3.30)$ ) and chronic lung disease (1.51 (95\% CI 1.21 to 1.89 ) $/ 1.43$ (95\% CI 1.09 to 1.88)) were higher while those of arthritis ( 0.70 (95\% CI 0.58 to 0.84$) / 0.66$ (95\% CI 0.54 to 0.80$)$ ) were lower in men compared with women in both middle-aged and elderly groups. However, the odds of heart disease (0.65 (95\% CI 0.52 to 0.80$)$ ) remained lower in men compared with women among middle-aged study participants only.

\section{DISCUSSION}

We observed marked sex differences in self-reported NCD prevalence among Chinese adults aged 45 years and older who participated in the CHARLS nationally representative study in 2011. In both middle-aged and elderly sub-groups, odds of arthritis were lower while those of stroke and chronic lung disease were higher in men than in women. However, odds of heart disease were lower in men than in women, but only in the group of individuals aged 45-64 years. These associations were independent of age, education, marital status, region in China, urban residence, physical activity, smoking, alcohol consumption and number of meals eaten each day. The present study provides a better understanding of sex differences in NCDs in middle-aged and older adults in China. Identifying and targeting groups at high risk for NCDs may improve healthcare delivery and help with planning approaches for primary and secondary prevention of NCDs in middle-aged and older adults in China.

Our study found that women were more likely than men to report worse self-rated health and having arthritis and less likely to report a history of stroke and chronic lung diseases. These findings are in line with previous similar research in several regions and countries including Latin America, China and India. The prevalence of rheumatoid arthritis was five times higher in women than in men in Latin America, ${ }^{18}$ while Zhong et al reported that the prevalence of COPD was higher in men $(12.4 \%)$ than in women $(5.1 \%)$ among 20245 participants aged 40 years or older in seven provinces/cities in China. ${ }^{19}$ Similar to our findings, investigators from India have also reported worse health in women compared with men. ${ }^{20}$
The sex differences in tobacco smoking and alcohol consumption observed in our study are also consistent with previous research. Chen et al conducted two nationwide prospective studies 15 years apart and found that only $2 \%$ of Chinese women smoked compared with over $60 \%$ of their male counterparts. ${ }^{21}$ Furthermore, the tobacco-attributed proportion of mortality is higher among men than among women. It is estimated that smoking will cause about $20 \%$ of all adult male deaths in China during the decade starting in 2010. ${ }^{21}{ }^{22}$ Similar to the findings in our study, the prevalence of male and female current alcohol drinking was $55.6 \%$ and $15.0 \%$ in another nationally representative study of Chinese men and women from 31 provinces in China in 2007. ${ }^{23}$

Sex differences in the prevalence of hypertension, diabetes and heart disease observed in our study were not always consistent with findings from previous studies. ${ }^{24-28}$ For example, Yang W et al reported that the prevalence of diabetes among Chinese adults aged 20 years or older was $9.7 \%$, which is higher than that in our study (5-8\%), and male sex was significantly associated with an increased risk of diabetes. We observed odds of diabetes that were lower in men than in women for individuals aged 65 years or older. The discrepancy in the results may have been due to differences in the age of the studied population and the way diabetes was determined. In the study by Yang et al, study participants were on average younger and diabetes diagnosis was defined by a blood glucose level and not self-reported. Our results also contrast with the results of the study of Yang $\mathrm{L} e t a t^{28}$ who reported that the prevalence of hypertension was higher in men than in women aged 15 or older in China. There was a difference in the age distribution of the populations between the studies that may contribute to the discrepancy in the findings. In addition, many potential confounding variables such as physical activity and diet were not adjusted for in the study by Yang $\mathrm{L} e t a l^{28}$

The results of our study indicate that women were more likely to report having heart disease than men, which was consistent with the results reported in some low- and middle-income countries, but not in most high-income countries. ${ }^{29-31}$ This may be a result of lower healthcare seeking by women than by men, as it has been reported that, in developing countries, men use health services more frequently than women. ${ }^{32}$ Indeed, in a study exploring gender differences in the use of healthcare in China, there was a greater use of healthcare in men than in women. ${ }^{33}$ Men also tended to have a longer duration of hospitalisation and to spend more on hospitalisation than women, while greater use of healthcare in women compared with men was observed only during women's childbearing years. ${ }^{33}$ Chinese cultural gender norms and values mean that preferential treatment is often given to male family members because of their greater economic contribution. ${ }^{33}$ Additionally, women in China often tend to postpone their own health-seeking behaviour until really necessary in order to preserve the family's funds, which may result in a detrimental effect on their health and longevity. ${ }^{35}$ 
It is frequently observed that women have poorer self-reported health than men. ${ }^{22}{ }^{36-38}$ In our study, we also found that women were more likely to report certain NCDs and poorer self-rated health than men. One potential explanation is that women have a higher prevalence of degenerative but non-fatal conditions such as arthritis and other painful conditions, hypertension and/or vision problems than men, while men may experience more severe NCDs. ${ }^{36} \mathrm{~A}$ mix of biological factors and societal gender inequalities have been proposed as major contributing factors to gender gaps in self-reported measures of health. ${ }^{37}$ Previous research has also demonstrated that widowed women have much higher risks of reporting poor self-rated health than married women. ${ }^{39}$ In our study, it is notable that a larger proportion of women than men reported being widowed, which may have also contributed to gender disparities.

Socioeconomic status may also have contributed to the differences in health between women and men. The association between educational attainment and health outcomes has been well established. ${ }^{40}$ It has been found that better educated individuals report better health and have fewer chronic diseases than those with lower levels of formal education. ${ }^{41}$ Therefore, in our study the lower education attainment of women compared with men may have contributed to women reporting worse overall health. However, it is important to note that marriage motivates couples to share health resources, exchange knowledge about prevention and treatment of illnesses, ${ }^{42}$ and share lifestyle and attitudes. ${ }^{43}$ In a recent study that examined the association between spousal education and self-rated health among married men and women in the USA, being married to a highly educated person was associated with lower odds of reporting fair or poor health. ${ }^{44}$ Similarly, in a Norwegian study ${ }^{42}$ that explored the relationship between the educational achievements of family members and mortality, the education of the spouse was negatively associated with mortality. Interestingly, the investigators observed that the education of spouses had a weaker effect on health than individuals' own education, both for men and women. ${ }^{42}$ In addition, there are also gender inequalities in earnings whereby women get paid less than men, even for equivalent work; and girls and women lag behind in education and employment opportunities, which continue to damage the health of millions of girls and women worldwide. ${ }^{21} 4546$ It is therefore possible that the proportion of each NCD that is undiagnosed is greater in women than men as a result of these socioeconomic and cultural norms in healthcare seeking. The sex difference in the combined prevalence of both diagnosed and undiagnosed disease ("true prevalence') of conditions that we have found to be more common in women may have been underestimated, but sex differences in the true prevalence of conditions that we have found to be less common in women may have been overestimated by using self-reported outcomes.

There are several limitations to the study. This study is cross-sectional, and is therefore simply descriptive and may be influenced by survival bias. Longitudinal studies are needed to determine whether the sex differences persist or change over time and whether they differ for younger and older population groups. The study is representative of people from China aged 45 years and older; however, the findings may not apply to younger population groups. Furthermore, sociodemographic characteristics and health-related behaviours were self-reported and hence prone to recall bias, which may affect men and women differently. Health outcomes were also self-reported and may differ from those noted in medical records. This discrepancy could be due to recall bias and may differ between men and women. This discrepancy may also be due to poor communication between a patient and a health professional, health literacy of the patient, and patients may also report conditions for which they have been tested but not diagnosed, or they may self-diagnose if they were not satisfied with the doctor's explanation for their health complaint. ${ }^{47}$ Multiple statistical tests were performed, which may have led to false positive results, and the large sample size may give statistically significant results that are not clinically important. The analyses were adjusted for several potential confounding factors; however, the results may still be confounded by other known and unknown factors. The strengths of the study lie in the use of a nationally representative sample of adults aged 45 years or older, multiple reported health outcomes and consideration of multiple factors that can potentially confound or mediate the relationship between sex and health.

\section{CONCLUSIONS}

In our study, in both middle-aged and elderly subgroups, the odds of self-reported arthritis were lower in men than in women while the odds of stroke and chronic lung disease were higher in men than in women. The odds of heart disease were also lower in men than in women, but only in the group of individuals aged 45-64 years. We argue for a greater focus on sex differences in common health problems and a gendered approach to monitoring, policy and intervention in the control of NCDs.

Contributors YL conceptualised and designed the study, analysed and interpreted data, drafted the manuscript, critically revised the manuscript for important intellectual content and approved the final manuscript as submitted. GL conceptualised and designed the study, acquired and analysed data, drafted the manuscript and approved the final manuscript as submitted. HW conceptualised and designed the study, drafted the manuscript and approved the final manuscript as submitted. WJ and SW conceptualised and designed the study, critically revised the manuscript for important intellectual content and approved the final manuscript as submitted. DG conceptualised and designed the study, interpreted data, drafted the manuscript, critically revised the manuscript for important intellectual content and approved the final manuscript as submitted. All authors read and approved the final manuscript.

Competing interests None declared.

Patient consent Obtained.

Ethics approval The original CHARLS was approved by the ethics review committee of Peking University, and all participants gave written informed consent at the time of participation. 
Provenance and peer review Not commissioned; externally peer reviewed.

Data sharing statement № additional data are available.

Open Access This is an Open Access article distributed in accordance with the Creative Commons Attribution Non Commercial (CC BY-NC 4.0) license, which permits others to distribute, remix, adapt, build upon this work non-commercially, and license their derivative works on different terms, provided the original work is properly cited and the use is non-commercial. See: http://creativecommons.org/ licenses/by-nc/4.0/

(C) Article author(s) (or their employer(s) unless otherwise stated in the text of the article) 2017. All rights reserved. No commercial use is permitted unless otherwise expressly granted.

\section{REFERENCES}

1. World Health Organization. Global status report on noncommunicable diseases, 2014. http://apps.who.int/nmh/ publications/ncd-status-report-2014/en/index.html (accessed 27 Oct 2017)

2. Lozano R, Naghavi M, Foreman K, et al. Global and regional mortality from 235 causes of death for 20 age groups in 1990 and 2010: a systematic analysis for the Global Burden of Disease Study 2010. Lancet 2012;380:2095-128.

3. Macintyre S, Hunt K, Sweeting H. Gender differences in health: are things really as simple as they seem? Soc Sci Med 1996;42:617-24.

4. Verbrugge LM. Sex differentials in morbidity and mortality in the United States. Soc Biol 1976;23:275-96.

5. Case A, Paxson C. Sex differences in morbidity and mortality. Demography 2005;42:189-214.

6. Crimmins EM, Kim JK, Solé-Auró A. Gender differences in health: results from SHARE, ELSA and HRS. Eur J Public Health 2011;21:81-91.

7. Wandera SO, Kwagala B, Ntozi J. Prevalence and risk factors for self-reported non-communicable diseases among older Ugandans: a cross-sectional study. Glob Health Action 2015;8:27923.

8. Zhou M, Wang H, Zhu J, et al. Cause-specific mortality for 240 causes in China during 1990-2013: a systematic subnational analysis for the Global Burden of Disease Study 2013. Lancet 2016;387:251-72.

9. Sun $\mathrm{H}$, Zhang Q, Luo X, et al. Changes of adult population health status in China from 2003 to 2008. PLoS One 2011;6:e28411.

10. National Health and Family Planning Commission of the People's Republic of China. Chinese health yearbook. http://www.nhfpc.gov. cn/htmlfiles/zwgkzt/ptjnj/year2013/index2013.html (accessed 20 Oct 2016)

11. Yang W, Lu J, Weng J, et al. Prevalence of diabetes among men and women in china. N Engl J Med Overseas Ed 2010;362:1090-101.

12. Li YC, Wang LM, Jiang $\mathrm{Y}$, et al. [Prevalence of hypertension among Chinese adults in 2010]. Zhonghua Yu Fang Yi Xue Za Zhi 2012;46:409-13.

13. Wang $\mathrm{ZH}$, Wang LH, Li YC, et al. [Current status of diabetes, hypertension and dyslipidemia among older Chinese adults in 2010]. Zhonghua Yu Fang Yi Xue Za Zhi 2012;46:922-6.

14. Zhong N, Wang C, Yao W, et al. Prevalence of chronic obstructive pulmonary disease in China: a large, population-based survey. Am J Respir Crit Care Med 2007;176:753-60.

15. National Health and Family Planning Commission of the PRC. 2015 report on Chinese resident's nutrition and chronic disease. http:// www.moh.gov.cn/jkj/s5879/201506/4505528e65f3460fb886850 81ff158a2.shtml (accessed 20 Oct 2016).

16. Galdas PM, Cheater F, Marshall P. Men and health help-seeking behaviour: literature review. J Adv Nurs 2005;49:616-23.

17. World Health Organization. The World Health Report 2002: reducing risks, promoting healthy life, 2002. http://www.who.int/whr/2002/en/ (accessed 2 Jul 2017).

18. Barragán-Martínez C, Amaya-Amaya J, Pineda-Tamayo R, et al. Gender differences in Latin-American patients with rheumatoid arthritis. Gend Med 2012;9:490-510.

19. Zhong N, Wang C, Yao W, et al. Prevalence of chronic obstructive pulmonary disease in China. Am J Respir Crit Care Med 2007;176:753-60.

20. Bora JK, Saikia N. Gender differentials in self-rated health and self-reported disability among adults in India. PLoS One 2015;10:e0141953.
21. Chen Z, Peto R, Zhou M, et al. Contrasting male and female trends in tobacco-attributed mortality in China: evidence from successive nationwide prospective cohort studies. Lancet 2015;386:1447-56.

22. Boerma T, Hosseinpoor AR, Verdes E, et al. A global assessment of the gender gap in self-reported health with survey data from 59 countries. BMC Public Health 2016;16:675.

23. Li $Y$, Jiang $Y$, Zhang $M$, et al. Drinking behaviour among men and women in China: the 2007 China chronic disease and risk factor surveillance. Addiction 2011;106:1946-56.

24. Minh HV, Byass P, Chuc NT, et al. Gender differences in prevalence and socioeconomic determinants of hypertension: findings from the WHO STEPs survey in a rural community of Vietnam. J Hum Hypertens 2006;20:109-15.

25. Xu Y, Wang L, He J, et al. Prevalence and control of diabetes in Chinese adults. JAMA 2013;310:948-59.

26. Crimmins EM, Kim JK, Solé-Auró A. Gender differences in health: results from SHARE, ELSA and HRS. Eur J Public Health 2011;21:81-91.

27. Yang W, Pan CY, Tou C, et al. Efficacy and safety of saxagliptin added to metformin in Asian people with type 2 diabetes mellitus: a randomized controlled trial. Diabetes Res Clin Pract 2011;94:217-24.

28. Yang L, Yan J, Tang $X$, et al. Prevalence, awareness, treatment, control and risk factors associated with hypertension among adults in Southern China, 2013. PLoS One 2016;11:e0146181.

29. Carrillo-Larco RM, Miranda JJ, Li X, et al. Prevalence of pragmatically defined high CV risk and its correlates in LMIC: a report from 10 LMIC areas in Africa, Asia, and South America. Glob Heart 2016;11:27.

30. Mosca L, Barrett-Connor E, Wenger NK. Sex/gender differences in cardiovascular disease prevention: what a difference a decade makes. Circulation 2011;124:2145-54.

31. George J, Rapsomaniki E, Pujades-Rodriguez M, et al. How does cardiovascular disease first present in women and men? Incidence of 12 cardiovascular diseases in a contemporary cohort of 1,937,360 people. Circulation 2015;132:1320-8.

32. Vlassoff $C$. Gender differences in determinants and consequences of health and illness. J Health Popul Nutr 2007;25:47.

33. Song Y, Bian Y. Gender differences in the use of health care in China: cross-sectional analysis. Int J Equity Health 2014;13:8.

34. Wang SJ. Reflection on the new rural cooperative medical system from the view of gender. Chinese Health Eco Magazine 2008;27:34-6.

35. Liu C, Bryson SA. Why informally employed Chinese women do not go to the doctor. Health Promot Int 2015;32:dav104.

36. Wingard DL, Cohn BA, Kaplan GA, et al. Sex differentials in morbidity and mortality risks examined by age and cause in the same cohort. Am J Epidemiol 1989;130:601-10.

37. Nathanson CA. Sex, illness, and medical care. A review of data, theory, and method. Soc Sci Med 1977;11:13-25.

38. Diaz MD. Socio-economic health inequalities in Brazil: gender and age effects. Health Econ 2002;11:141-54.

39. Perkins JM, Lee HY, James KS, et al. Marital status, widowhood duration, gender and health outcomes: a cross-sectional study among older adults in India. BMC Public Health 2016;16:1032.

40. Hummer RA, Lariscy J. Educational attainment and adult mortality. In: Rogers RG, Crimmins EM, eds. International handbook of adult mortality. Dordrecht, The Netherlands, 2011:241-61.

41 UNICEF. State of the World's Children 2007. Women and children: the double dividend of gender equality. http://www.unicef.org/sowc07/ report/full_report.php (accessed 20 Oct 2016).

42. Kravdal $\varnothing$. A broader perspective on education and mortality: are we influenced by other people's education? Soc Sci Med 2008;66:620-36.

43. Monden CW, de Graaf ND, Kraaykamp G. How important are parents and partners for smoking cessation in adulthood? An event history analysis. Prev Med 2003;36:197-203.

44. Brown DC, Hummer RA, Hayward MD. The importance of spousal education for the self-rated health of married adults in the United States. Popul Res Policy Rev 2014;33:127-51.

45. Marmot M, Friel S, Bell R, et al. Closing the gap in a generation: health equity through action on the social determinants of health. Lancet 2008;372:1661-9.

46. Guo Y, Xie Z. To bridge the gap with a generation-theory and international experience of social determinants of health. $J$ Peking University 2009;41:125-8.

47. Smith B, Chu LK, Smith TC, et al. Challenges of self-reported medical conditions and electronic medical records among members of a large military cohort. BMC Med Res Methodol 2008;8:37. 